\title{
MULTI-TEMPORAL FOREST COVER CHANGE AND FOREST DENSITY TREND DETECTION IN A MEDITERRANEAN ENVIRONMENT
}

\author{
Elias Symeonakis ${ }^{1 *}$, Peter A. Caccetta ${ }^{2}$, Jeremy F. Wallace ${ }^{2}$, Eva Arnau-Rosalen ${ }^{3}$, Adolfo Calvo-Cases ${ }^{3}$, Sotirios Koukoulas ${ }^{4}$ \\ ${ }^{1}$ School of Science \& Environment, Manchester Metropolitan University, Manchester M15 GD, UK \\ ${ }^{2}$ CSIRO Mathematical and Information Sciences, Private Bag 5, Wembley 6913, Australia \\ ${ }^{3}$ Department of Geography, University of Valencia, Av. Blasco Ibáñez 28, Valencia 46010, Spain \\ ${ }^{4}$ Department of Geography, University of the Aegean, Lofos Panepistimiou, Mytilene 81100, Greece
}

Received: 27 July 2014; Revised: 31 May 2015; Accepted: 1 June 2015

\section{ABSTRACT}

The loss of forests along with the various types of shrubs in the Mediterranean region is seen as an important driver of climate change and has been repeatedly related with the observed land degradation and desertification in the region. Nevertheless, the extent of woody perennial vegetation cover (WPVC) and its density remain largely unclear. Here, we apply a series of algorithms and methods operationally used in Australia for large-scale WPVC mapping and monitoring and demonstrate their applicability in the Mediterranean region using a Spanish area as the trial site. Five Landsat TM and ETM+ images from various dates spanning 14 years are used to map changes in the extent of WPVC and to identify areas with a declining, stabilising or recovering trend. Results show that the applied methodology, which incorporates (i) preprocessing of the Landsat imagery, (ii) a canonical variate analysis to spectrally discriminate between woody and non-woody land cover types, (iii) a conditional probability network and (iv) spectral indices for mapping woody cover and density trend, is highly successful and well suited for use in Mediterranean environments. A rigorous accuracy assessment is undertaken producing overall accuracies above 97\% for both woody and non-woody cover types and all dates. Results also show that in the area of study, the majority of WPVC disturbances were due to forest fires, which represent the region's most frequent natural and anthropogenic disturbance. This raises significant concerns about the future of the area's WPVC. Regeneration compensated to some degree for the high disturbance rates. Copyright (C) 2015 John Wiley \& Sons, Ltd.

KEY WORDS: forest cover; change detection; classification; multi-temporal; Landsat; Mediterranean; density trends; conditional probability network

\section{INTRODUCTION}

Vegetation acts as an important protective layer for the soil. Its removal by fire, overgrazing or clearing for agriculture is related to increased rates of surface runoff, soil erosion and land degradation (Cerdà \& Doerr, 2005; Barua \& Haque, 2013; Bravo-Espinosa et al., 2014; QuiñoneroRubio et al., 2015). Changes in woody perennial vegetation cover (WPVC) are, therefore, important to monitor, as they are also renowned to directly and indirectly affect biodiversity, climate change and human living conditions (MA, 2005; Bonan, 2008; Kuemmerle et al., 2009; Hansen et al., 2013; Lee et al., 2013; Griffiths et al., 2014). Over the last decades, it has increasingly become of international concern to map and monitor WPVC changes, especially with the rising effect of human pressure on the planet (Hansen et al., 2008; Liu et al., 2013).

Traditionally, forest cover inventories from national institutions and agencies have been used to track the evolution of forested areas (Hilker et al., 2008). Over the last decades, in an attempt to curb the limitations of such inventories (e.g. inconsistency of survey methods and lack

*Correspondence to: E. Symeonakis, School of Science \& Environment, Manchester Metropolitan University, Manchester M15 GD, UK

E-mail: e.symeonakis@mmu.ac.uk of resources for quality assessment and updating), this is all the more attempted by using Earth observation data, because monitoring techniques based on multispectral satellite-acquired data have demonstrated potential as a means to detect, identify and map changes in forest cover (Coppin \& Bauer, 1994; Coppin \& Bauer, 1996; MuñozVillers \& López-Blanco, 2008; Röder et al., 2008; Gill et al., 2009; Nilsson et al., 2009). Nevertheless, major challenges still remain. Per-pixel classification methods have most commonly been applied with varying degrees of success: hurdles are introduced by the very nature of the specific cover type (e.g. phenological differences, shadows produced from vegetation itself, substantial variability in vegetation communities and complex terrain gradients), resulting in intricate and intertwined thematic classes (Muñoz-Villers \& López-Blanco, 2008; Röder et al., 2008; Gill et al., 2009; Kuemmerle et al., 2009; Nilsson et al., 2009; Margono et al., 2012).

Comprehensive reviews of different change detection approaches using Earth observation data have been provided in the literature (Coppin et al., 2004). Crude 'from-to' assessments have typically been employed, along with a variety of methods that analyse bi-temporal change (Coppin et al., 2004). The majority of algorithms apply a postclassification comparison (Onur et al., 2009) or, less frequently, contextual classifiers (Magnussen et al., 2004) 
or an image-to-image comparison between different dates (Berberoglu \& Akin, 2009). Although post-classification comparison methods are successful in identifying the location, extent and nature of changes (Foody, 2002), they often lead to the identification of false change due to single-date classification omission and commission errors (Foody \& Boyd, 1999). The image archives available nowadays permit the shifting towards more sophisticated multi-date change analysis techniques (Kennedy et al., 2007; Huang et al., 2010). Unfortunately, the complexity of such analyses increases exponentially with every added image, and, as Kuemmerle et al. (2009) suggest, it is probably best to accurately classify individual images first and assess change a posteriori.

To improve the efficiency of a forest cover change analysis, Kennedy et al. (2007) developed a trajectory-based change detection algorithm using multi-temporal Landsat data. They identified as primary source of error in their analysis the mis-registration of images in a stack. Bodart et al. (2011), under the auspices of the Joint Research Centre of the European Commission TREES-3 project, developed a pre-processing chain of multi-temporal Landsat data for classifying tropical forests using an object-based supervised classification approach. They argue, as do Hansen et al. (2008), that misclassification of forest changes is greatly restrained by reducing the effect of external factors, such as differences in atmospheric conditions, temporal variations in the illumination and viewing angles and sensor calibration inconsistency. Huang et al. (2010) also suggest a methodology for the production of forest disturbance maps based on dense Landsat time-series stacks and the spectral-temporal properties of closed or near-closed canopy forests. Their method first creates imagery with minimum (cloud and shadow) contaminations and minimum instrument or processing-related errors and then tracks forest disturbances using index values of bands 3, 5 and 7. Their automated approach identified most disturbances but fell short of identifying some types of clearing and labelled as disturbances some non-forest land cover types.

In Australia, an operational methodology was devised by the Commonwealth Scientific and Industrial Research Organisation (CSIRO) for mapping and monitoring the extent of WPVC for the entire Australian continent (Caccetta et al., 2007; Lehmann et al., 2012). As in the case of Hansen et al. (2008) and Bodart et al. (2011), the CSIRO methodology places emphasis on the creation of consistent time-series Landsat data, before it moves on to apply a multi-temporal classification scheme (Furby, 2002; Caccetta et al., 2003) with a view to minimise commission and omission errors due to individual-year image classification errors. The methodology also maps the increasing, decreasing or stabilising trend in the density of WPVC, which is appropriate for the identification of areas that warrant attention and the adaptation of mitigation, reforestation or other land management policies.

Here, our main aim is to use the CSIRO methodology in a Spanish area as a trial of its applicability in a Mediterranean environment. The area has been subjected to major changes in WPVC, mainly pine forests of the Pinus halepensis Miller species and Mediterranean shrubs (matorral or maquis, typically consisting of densely growing evergreen shrubs), as a result of forest fires (Cerdà et al., 1995; Bodí et al., 2011), the abandonment of agricultural and grazing land (Bonet 2004; Chrenková et al., 2014), the transition to a more industrial and tourism-oriented economy and the intensification of agriculture, among others (Symeonakis et al., 2007). Forest fires are particularly seen as one of the most important drivers of the observed land degradation in the region (González-Alonso et al., 2007), as thousands of hectares of forest and scrubland are destroyed each year: only in the first 7 months of 2009, for example, fires burned some 75,000 ha of WPVC (AFP, 2009). There is, therefore, a need for accurate monitoring methods that would allow for the identification of any decreasing forest cover trend and the adaptation of measures for its reversal.

Within this main aim, our specific objectives are as follows:

- to map WPVC, WPVC change and WPVC density trends in the period between 1987 and 2001 in a Spanish area using Landsat imagery and the CSIRO methodology and

- to carry out a validation of the multi-temporal classifications using aerial photography in order to assess the performance of the methodology in the study area.

\section{MATERIALS AND METHODS}

\section{Study Area}

The trial site in Spain is composed by a system of valleys (Cànyoles and Albaida valleys) and mountain ranges (Serra d' Enguera, Grossa and de la Solana) belonging to the Prebetic system (SW-NE direction). It covers an area of approximately $550 \mathrm{~km}^{2}$ (Figure 1) and is characterised by a complex topography, which ranges between 250 and 1,000 $\mathrm{m}$ asl. The basins are Miocene marls, whereas the ranges are mainly composed of Cretaceous limestones. The climate is Mediterranean, with hot and very dry summers, and higher precipitation amounts in the autumn. The Cànyoles watershed exhibits a dry semiarid Mediterranean climate, with dry and hot summers and warm winters. Temperatures are highest in July and August with mean daily values of $25^{\circ}$ $\mathrm{C}$; January is the coldest month (mean daily values of $10^{\circ} \mathrm{C}$ ). Mean annual rainfall ranges from $693 \mathrm{~mm}$ per year at the Xàtiva gauge station in the eastern part of the basin to $500 \mathrm{~mm}$ per year at the Almansa gauge station in the western part of the study area. Mean annual evapotranspiration exceeds $1,000 \mathrm{~mm}$ per year. . Natural vegetation is mainly developed on the range systems and on limited soil depths. It is composed of Pinus halepensis Miller and Mediterranean sclerophic scrubs, such as Pistacia lentiscus L., Quercus coccifera L., Rosmarinus officinalis L. and Ulex parviflorus Pourr., with different density and continuity in the cover according to its degradation state (Cerdà \& Doerr, 

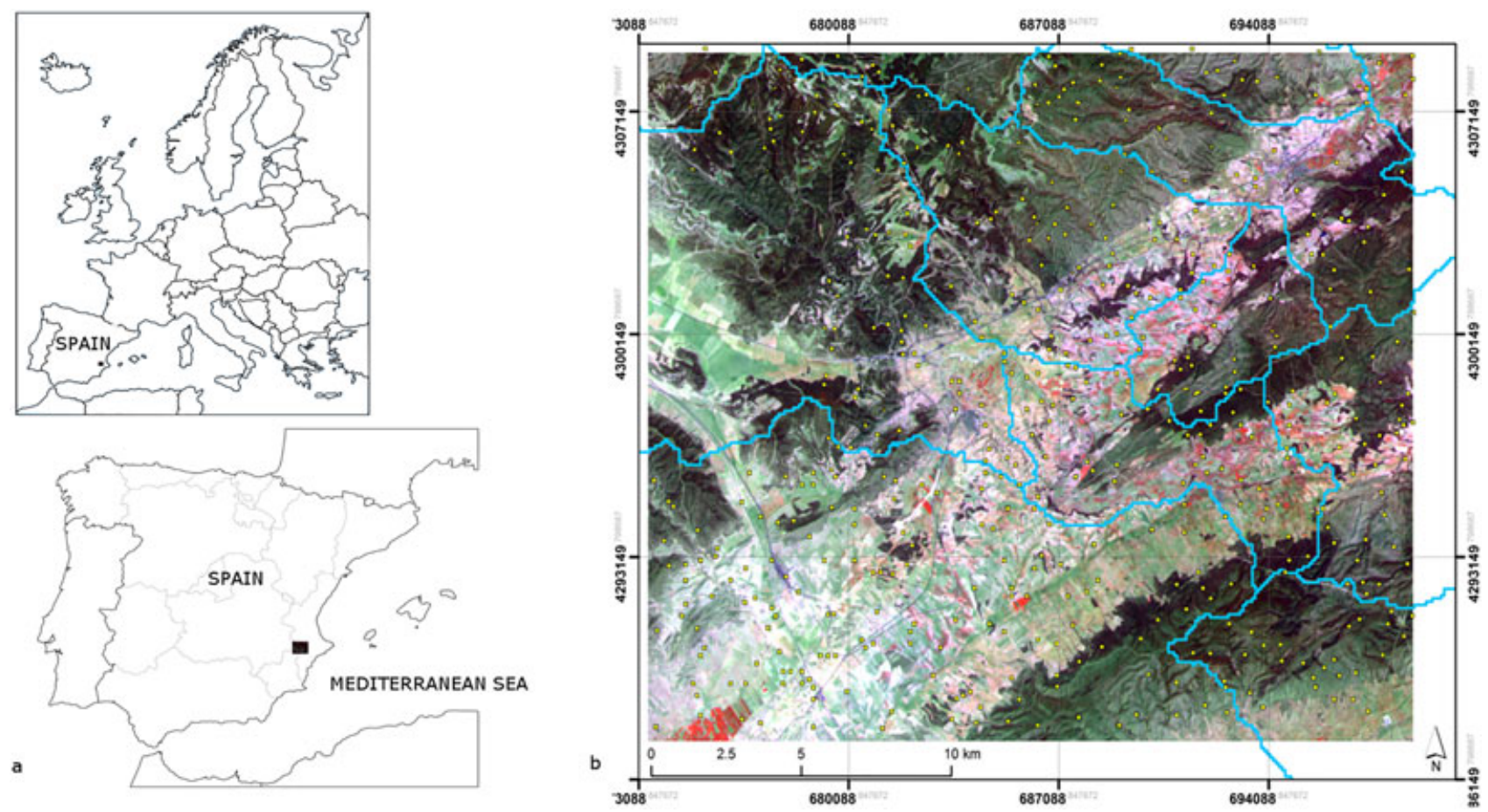

Figure 1. (a) Location of study area within Europe and Spain. (b) Study area, watershed boundaries (in light blue) and distribution of validation samples (yellow rectangles) for the 2001 image using a stratified random approach (non-woody polygons: 353; woody polygons: 169). This figure is available in colour online at wileyonlinelibrary.com/journal/ldr.

2007). Nevertheless, the valleys are extensively cultivated with unirrigated types such as olive trees and vineyards. Residential and urban use in the area maintains a predominant concentrated model. Under such environmental conditions and human pressure, forest fires are a frequent phenomenon (Cerdà et al., 1995; Cerdà 1998; Cerdà \& Doerr, 2005).

\section{Satellite and Ancillary Data}

Five TM and ETM+ images (path: 199, row: 33) from the National Aeronautics and Space Administration GeoCover archive (Tucker et al., 2004) were used spanning 14 years from 1987 to 2001 (Table I).

The time series Landsat data were registered to WGS84 (Universal Transverse Mercator projection; zone 30 North). The Shuttle Radar Topography Mission digital elevation model of the United States Geological Survey with a horizontal resolution of $90 \mathrm{~m}$ was used for the orthorectification process, which plays a critical role in the whole change mapping process. If time-series images are not co-registered accurately, the same pixel on different images will be shifted causing serious problems for tracking land cover change through time. The 2001 image was chosen as the reference for the co-registration, and roughly 100 points were used. Although the overall size of the mean errors (root-meansquare deviation) was around $10 \mathrm{~m}$ in both directions for all images, which is less than one pixel, it is the absolute pixel errors of more than one pixel, which are a cause of concern in multi-temporal studies. According to an imagematching programme used, two concentrations of relatively low values were detected on the $x$-direction, indicative of the care required for using such data for multi-temporal mapping of land use/cover changes.

Ideally, local knowledge, ground data and high-resolution aerial/satellite images are used to identify sites of desired land cover types in the study area and their change through time. However, it is often the case that training and validation data exist only for a limited number of dates. In

Table I. Landsat imagery used (Tucker et al., 2004), classification accuracies (\%) of the woody (W) and the non-woody perennial vegetation (NW) cover maps for each image and area covered by the validation polygons for each type and epoch

\begin{tabular}{|c|c|c|c|c|c|c|c|c|c|c|c|c|}
\hline & \multirow{2}{*}{$\begin{array}{l}\text { Sensor and } \\
\text { aquisition date }\end{array}$} & \multirow{2}{*}{$\begin{array}{c}\text { Overall } \\
\text { accuracy } \\
(\%)\end{array}$} & \multirow[b]{2}{*}{ Kappa } & \multicolumn{2}{|c|}{ Correct } & \multicolumn{2}{|c|}{$\begin{array}{l}\text { Commission } \\
\text { errors }\end{array}$} & \multicolumn{2}{|c|}{$\begin{array}{l}\text { Omission } \\
\text { errors }\end{array}$} & \multicolumn{3}{|c|}{$\begin{array}{l}\text { Area of reference polygons } \\
\text { (pixels) }\end{array}$} \\
\hline & & & & W & NW & W & NW & W & NW & W & NW & Total \\
\hline 1987 & TM5, 13/08/1987 & $96 \cdot 82$ & 0.94 & 0.97 & 0.97 & 0.03 & 0.03 & 0.03 & 0.03 & 4,064 & 7,920 & 11,984 \\
\hline 1992 & TM5, 20/06/1992 & $97 \cdot 62$ & 0.95 & 0.99 & $0 \cdot 96$ & 0.04 & $0 \cdot 01$ & $0 \cdot 01$ & $0 \cdot 04$ & 3,872 & 8,144 & 12,000 \\
\hline 1994 & TM5, 29/06/1994 & $96 \cdot 81$ & 0.94 & 0.98 & 0.95 & 0.05 & 0.02 & $0 \cdot 02$ & 0.05 & 3,872 & 8,144 & 12,000 \\
\hline 2000 & ETM+, 08/08/2000 & 97.93 & $0 \cdot 96$ & 0.98 & $0 \cdot 98$ & 0.02 & 0.02 & $0 \cdot 02$ & $0 \cdot 02$ & 3,920 & 7,840 & 11,760 \\
\hline 2001 & ETM+, 08/06/2001 & $96 \cdot 94$ & 0.94 & 0.98 & $0 \cdot 96$ & $0 \cdot 04$ & $0 \cdot 02$ & $0 \cdot 02$ & $0 \cdot 04$ & 3,184 & 8,016 & 11,200 \\
\hline
\end{tabular}


this study, training and validation data came from the sources shown in Table II. The validation area was reduced to $90 \%$ of the original study area because of issues related with the availability of ground reference data for the entire period of study.

Validation of the WPVC maps, which included forest and open shrub land, was performed by photo interpretation using homogeneous polygons as sampling units in a stratified random sampling frame across the woody and non-woody areas. First, we created around 500 polygons across the study area. The number of polygons per cover type (woody and non-woody) was proportional to the area covered by each type in each year. The polygon positions were randomly defined as points with a minimum distance of $200 \mathrm{~m}$ between them. The random points were converted to square polygons of $5 \times 5$ Landsat pixels. The sampling polygons were then reduced to homogeneous land-cover classes according to the reference aerial photos. In some cases, the shape and size of the polygons were altered to follow the ground cover morphology, making sure that they always measured the equivalent of at least four Landsat pixels. When a sample polygon was smaller, a new one was added to compensate. The area covered by the reference polygons for both (woody and non-woody) cover types is shown in Table I.

\section{Woody Perennial Vegetation Cover Mapping}

The orthorectified images were calibrated by converting their raw digital counts to be consistent with the reference image of 2001. Three calibration steps were applied, namely top-of-atmosphere reflectance calibration (Vermote et al., 1994), bi-directional reflectance distribution function calibration (Wu et al., 2001) and terrain illumination correction based on the C-correction (Teillet et al., 1982) and incorporating a ray-tracing algorithm for identifying true shadow (Wu et al., 2004).

Table II. Training and validation data (all URLs: accessed 25 February 2015)

\begin{tabular}{cccl}
\hline Year & \multicolumn{1}{c}{ Type } & Scale & \multicolumn{1}{c}{ Source } \\
\hline 1977 & $\begin{array}{l}\text { Aerial } \\
\text { photos }\end{array}$ & $1: 18,000$ & $\begin{array}{l}\text { Inter-ministerial or IRYDA } \\
\text { flight (Instituto Geográfico } \\
\text { Nacional-Centro Nacional de } \\
\text { Información Geográfica (IGN- } \\
\text { CNIG); WMS URL: http:// } \\
\text { fototeca.cnig.es) } \\
\text { Cartographic Institute of } \\
\text { Valencia (ICV; http://www. } \\
\text { icv.gva.es/) } \\
\text { Spanish national olive grove } \\
\text { registry (SIG-oleícola; http:// } \\
\text { www.oleohispana.com/sigo. } \\
\text { htm) } \\
\text { Aerial } \\
\text { photos }\end{array}$ Orthophotos \\
& $1: 25,000$ & $\begin{array}{l}\text { Spanish national agricultural } \\
\text { land registry (SIGPAC; http:// } \\
\text { wms.magrama.es/wms/wms. } \\
\text { aspx) }\end{array}$ \\
\hline
\end{tabular}

A large set of training samples was used to optimise the representation of environmental heterogeneity. A canonical variate analysis (CVA; Richards, 2013) was undertaken to investigate the spectral separability of the woody and nonwoody vegetation training samples. CVA is widely used to analyse group structures in multivariate data and as a means of separating a group of samples from different populations. In brief, CVA finds linear combinations of the original variables (Landsat bands, in this case) that maximise the separation between the different groups while minimising the within-group variance. Well-separated land cover types can be reliably mapped. The ordination plots from the CVA also provide the basis for grouping the training sites into spectrally consistent 'information classes' into which the image data can be classified. Moreover, the canonical vectors give the directions of maximum site separability, and the canonical roots give a measure of the amount of site separation in these directions.

Linear combinations of image bands, that is, indices, were then used to discriminate between the two classes. Figure 2a is an example canonical variate means plot for the training sites using the 2001 image data. It shows that woody and non-woody training sites are separable, although there are some non-woody sites that are spectrally similar to the woody training sites. This is an indication that the classes can be separated using two indices. In Figure 2a, they are separated by the first two canonical vectors; however, simpler indices were sought that are more robust through time. A contrast-directed CVA (Campbell \& Furby, 1994) was performed on the 2001 image to derive the following indices:

$$
\begin{gathered}
\text { Index } 1=\text { band } 3+\text { band } 5 \text {; and } \\
\text { Index } 2=\text { band } 4+\text { band } 2
\end{gathered}
$$

Thresholds that define the boundary between the certain woody vegetation spectral region and the uncertain spectral region were set so that no commission errors were made. Furthermore, additional thresholds were identified that distinguish between the uncertain areas and the certain non-woody vegetation spectral regions so that no omission errors were made. At first, these thresholds were identified from the training data. They were then refined by considering the entire image area. The previously applied calibration meant that the thresholds derived for the 2001 image could be applied to the rest of the images. The indices and thresholds were used to calculate a probability of woody cover image for each time frame in the following manner:

- $\operatorname{Pr}(\operatorname{woody})=1$, for pixels with index values in the 'certain woody vegetation' spectral region;

- $\operatorname{Pr}(\operatorname{woody})=0$, for pixels with index values in the 'certain non-woody vegetation' region; and

- $0<\operatorname{Pr}($ woody $)<1$, for pixels with index values in the uncertain spectral region (based on the closeness to the 'certain woody vegetation' thresholds). 

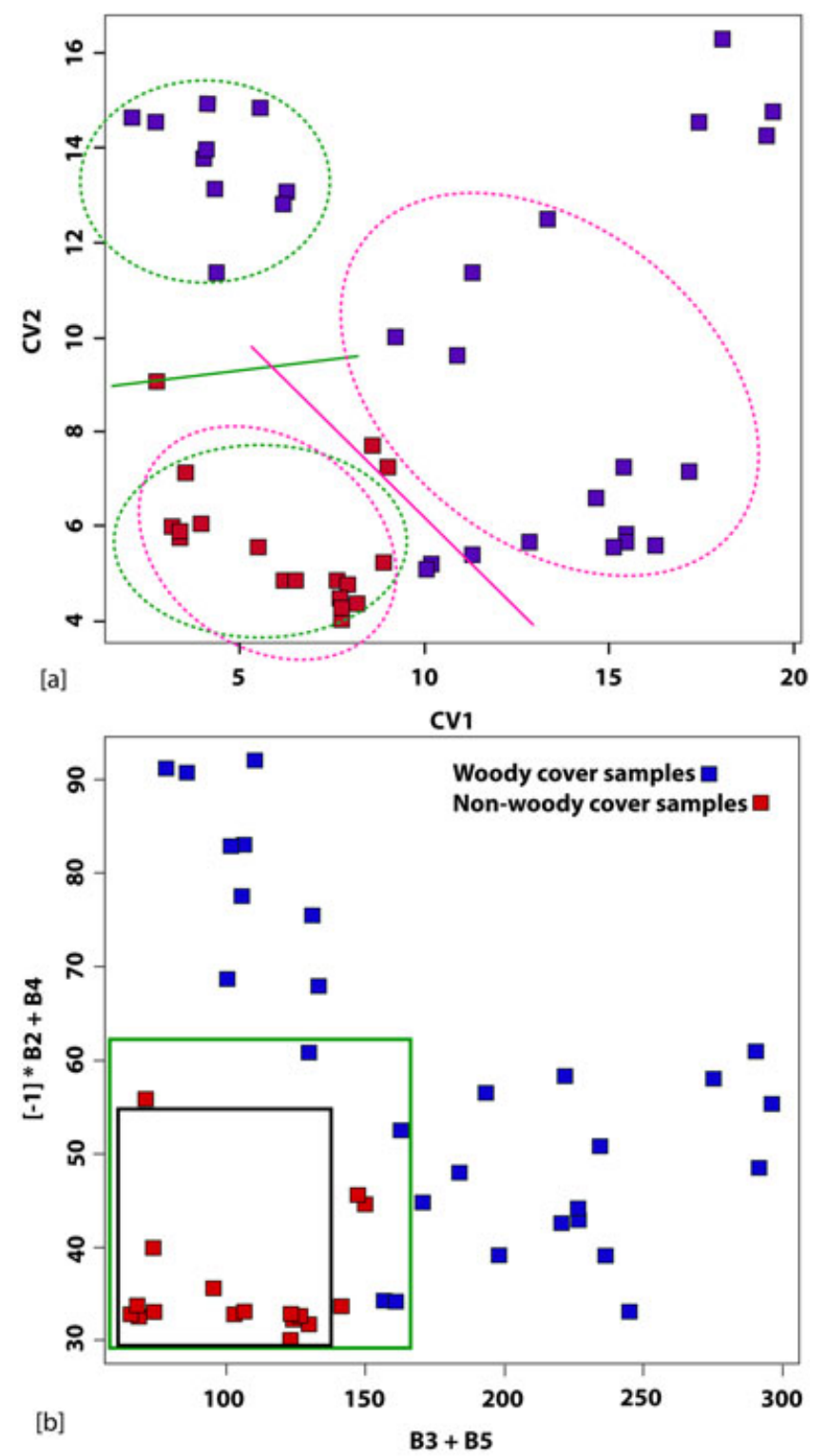

Figure 2. (a) Example of a canonical variate means plot for training sites from the 2001 data. The groupings of sites, or contrasts, used to derive the indices are depicted with the green and pink ellipses. (b) Index 2 versus index 1 plot for the same training sites from the 2001 image. 'Certain WPVC' sites are within the limits of the black box. 'Certain non-WPVC' sites are outside the limits of the green box. The 'uncertain' sites lie between the two boxes. WPVC, woody perennial vegetation cover. This figure is available in colour online at wileyonlinelibrary.com/journal/ldr.

Within the uncertain spectral region, additional information was used to label a pixel as 'woody' or 'non-woody'. This was derived from the pattern of index values through time.

A joint model for multi-temporal classification using conditional probability networks (CPNs; Kiiveri \& Caccetta, 1998; Kiiveri et al., 2001) was then specified. The CPNs provide a probabilistic framework for combining data, typically with the view to classifying the data. In our case, the input to the CPN were the five woody cover probability images calculated from the indices and the thresholds and a series of files that describe the relationships, or rules, between the CPN variables, that is, the true and the estimated woody cover maps. This approach exploits the observation that many commission errors due to land management practices vary more rapidly compared with woody vegetation processes and therefore the temporal rules are used to minimise the probability that such areas are labelled 'woody vegetation' in any year. The output of the CPN was a new probability image for each epoch. These were the modified probabilities that were altered by the aforementioned rules providing more consistent woody cover estimates through the years.

\section{Analysis of Woody Perennial Vegetation Cover Change and Woody Perennial Vegetation Cover Density Trends}

WPVC masks for each date were formed from the modified probability maps produced by the CPN. These WPVC masks were then compared to provide an estimate of WPVC change through time. The output of the CPN, a continuous field valued between 0 and 1 , is the probability of a location being WPVC. To avoid bias, we converted the CPN outputs to woody/nonwoody (binary) maps using the 0.5 threshold. We summarise the overall accuracy, per cent correct, commission and omission errors and kappa statistic values in Table I.

The woody cover results for the five epochs may be summarised in a number of ways. To simplify the discussions here, we derived a simplified WPVC change map, as previously suggested by Kuemmerle et al. (2009), by grouping the four periods (i.e. 1987-1992, 1992-1994, 1994-2000 and 2000-2001) into two 7-year equal-interval slots: 1987-1994 and 1994-2001, roughly equal to the regeneration period of woody vegetation in the specific Mediterranean environment. We defined the following classes, which can also be seen in Figure 3a:

- two disturbance classes depending on the time of disturbance (i.e. the complete or near-complete removal of WPVC by natural human-driven processes, e.g. fires and clearing);

- two reforestation classes;

- two mixed (i.e. recovery and disturbance) classes; and

- the two permanent WPVC and non-WPVC classes.

The methodology also provides another monitoring tool, the WPVC density trends, that allows for an insight to the dynamic processes that ensue at the vegetative cover. It provides a tool for identifying not only the presence or absence of WPVC but also its density, whether that is decreasing (e.g. through fire) or increasing (e.g. reforestation) or going through more subtle changes brought about by natural processes, such as recovery, stabilisation or regression (Wallace et al., 2006; Lehmann et al., 2012). The methodology exploits changes in the value of the first index (Equation 1) through time being related to albedo as a surrogate for (the inverse of) WPVC density. Figure $4 \mathrm{~b}$ shows plots of the first index values (Equation 1) through time for six sites with different WPVC densities. Lower values of the index correspond to denser WPVC and higher values to less dense. Areas of increasing WPVC appear to have lower index values in the later years than in the earlier ones. Conversely, areas with decreasing WPVC show higher index values in the later years than in the earlier ones. Areas 


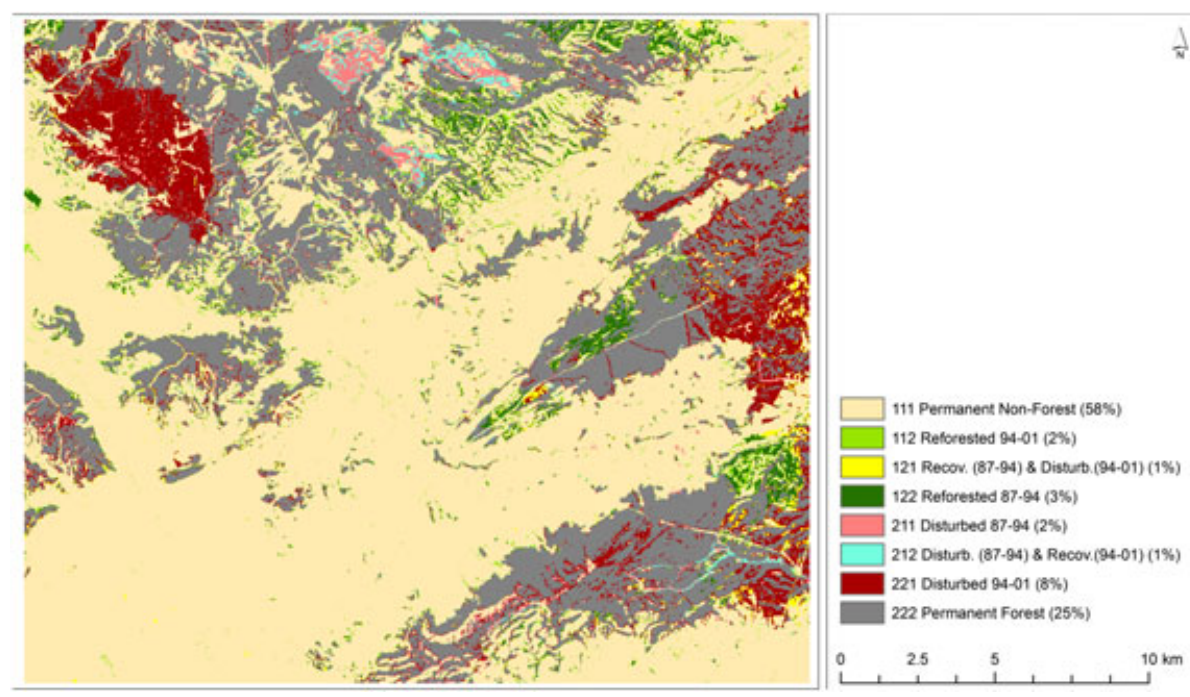

Figure 3. Spatial distribution of woody perennial vegetation cover changes and percentage of total area covered by the different change (disturbance and recovery) and stable (permanent woody and non-woody) classes for the periods 1987-1994 and 1994-2001. This figure is available in colour online at wileyonlinelibrary.com/journal/ldr.

that have been through some sort of disturbance (e.g. fire and grazing) but then recover have index values that are low in the early years, higher in the middle and then tend to return towards the lower values. These trends are summarised by fitting the linear and quadratic components (i.e. the slope and curvature) of the response of the first index through time. In order to obtain independent estimates of the two parameters, orthogonal polynomials are used for the fitting process (Draper \& Smith, 1981; Wallace et al., 2006). The summaries of change that are produced for each pixel are recorded as six bands, scaled to fit the 1-byte range (0-255; Table III).

\section{RESULTS AND DISCUSSION}

\section{Woody Perennial Vegetation Cover and Woody Perennial Vegetation Cover Change}

The classification as 'woody perennial vegetation' relies on the spectral contrasts of cover types resulting from physical differences on the ground and effectively requires a certain density of vegetation (Camacho-De Coca et al., 2004). Hence, thin, scattered vegetation with a high proportion of soil background may be omitted (Cohen et al., 2003). Certain dense but highly reflective vegetation types may also be omitted (Wu et al., 2005); however, no such cases were identified in this study, and our contextual classification approach resulted in highly reliable WPVC maps for all time periods. Table I shows the accuracy figures for the different dates for woody and non-woody cover types. Overall accuracies are between $96.81 \%$ and $97.93 \%$ and kappa values between 0.94 and 0.96 . Overall accuracy of our change map, estimated as the product of the individual map accuracies of Table I (Coppin et al., 2004), was $87 \%$ for the entire period (1987-2001), 92\% for the first half (1987-1994) and 92\% for the second half (1994-2001). In the 14-year period from 1987 to 2001, WPVC decreased from around 219 to $213 \mathrm{~km}^{2}$, and, consequently, non-woody areas increased by $6 \mathrm{~km}^{2}$, from 330 to $336 \mathrm{~km}^{2}$ (Table IV).

Disturbances were the main reason for these changes: those that occurred during the first period (1987-1994; classes 211 and 212 in Figure 3a) and those of the second period (1994-2001; classes 121 and 221 in Figure 3a). The total area covered by these disturbances together is about $66 \mathrm{~km}^{2}$, which represent $8 \%$ of the study area or $20 \%$ of the area that was WPVC in 1987. They appear clustered in the northwest, east and southeast where two major fire events took place in 1997 and 2001 (Figure 3b). Annual disturbance rates across the study area doubled in the second period: from $1.25 \%$ between 1987 and 1994 to $2.53 \%$ in 1994-2001.

During the 14-year period of study, regeneration occurred in $11 \%$ of all non-WPVC in 1987 (classes 112 and 122 in Figure $3 a)$ or in $5 \%$ of the total study area. The latter percentage is calculated by also including the areas that were covered by WPVC in the beginning of the period of study (i. e. 1987), suffered some disturbance between 1987 and 1994 but recovered in the second period (class 212 in Figure 3a). Recovery mainly occurred in three areas: one in the northeast, one in the centre and one in the southeast (Figure $3 b$ ). Regeneration annual rates are also on the increase, because they appear to be higher in the second period $(1.06 \%)$ than in the first $(0.81 \%)$.

Figure 5 presents four examples of disturbance and regeneration as captured by the (validation) aerial photography and mapped by our methodology: (i) area A, a case of agricultural expansion in a forested area, taking place in the first part of the study period (change code 211); (ii) area $\mathrm{B}$, a case of a fire breaker, which was picked up by our methodology only when it became wide enough in the second part of the period of study, that is, wider than a Landsat pixel (code 221); (iii) area $\mathrm{C}$, an area in the northwest representing a disturbance occurring in the second half through an extensive forest fire (code 221); and (iv) area 

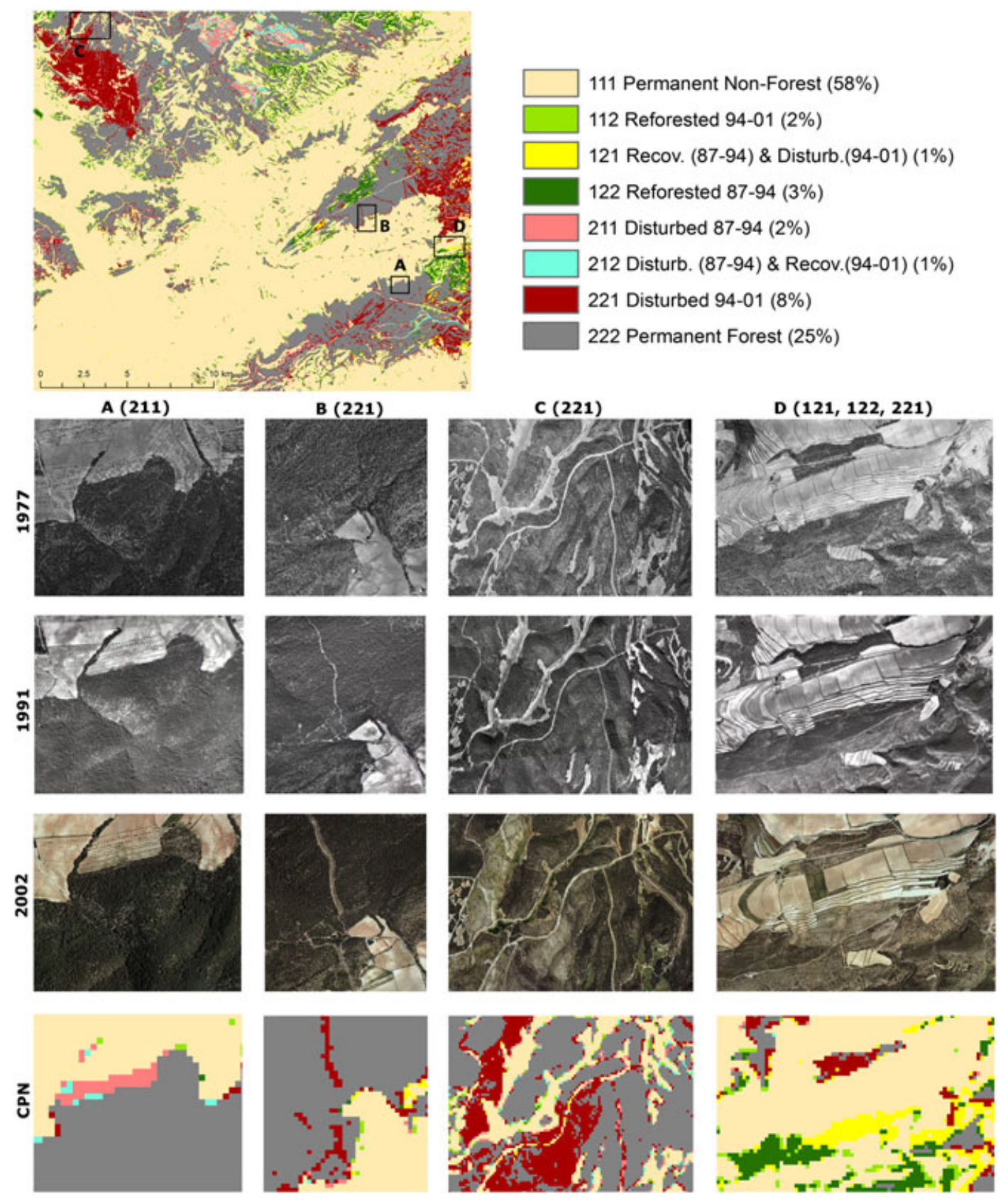

Figure 4. Temporal density trends for sample pixels showing areas of stable, improving and declining woody perennial vegetation cover as well as areas that have been disturbed and are recovering. This figure is available in colour online at wileyonlinelibrary.com/journal/ldr.

$\mathrm{D}$, on the eastern limits of the area of study, which includes a part that has recovered in the first half and is disturbed in the second (code 121), a part that is reforested in the first half

Table III. The six bands of the density trends file

\begin{tabular}{ll}
\hline Band & \multicolumn{1}{c}{ Description } \\
\hline 1 & Mean index brightness over all dates \\
2 & Linear trend (slope) in brightness over time (scaled) \\
3 & Quadratic trend (scaled) \\
4 & SD about mean (scaled) \\
5 & Residual SD after fitting linear trend (scaled) \\
6 & Residual SD after fitting linear and quadratic trend (scaled) \\
\hline
\end{tabular}

$\mathrm{SD}$, standard deviation. (code 122) and a part that is disturbed in the second half (code 221).

It is worth noting here that there is a time lag in the detection of revegetated areas, which varies with region and vegetation type. Hence, revegetated areas cannot be mapped

Table IV. Area $\left(\mathrm{km}^{2}\right)$ covered by the woody [woody perennial vegetation cover (WPVC)] and the non-woody (NW) perennial vegetation cover types in the five epochs

\begin{tabular}{lrrrrr}
\hline & 1987 & 1992 & 1994 & 2000 & 2001 \\
\hline NW & $330 \cdot 30$ & $318 \cdot 51$ & $327 \cdot 16$ & $326 \cdot 70$ & $336 \cdot 37$ \\
WPVC & $219 \cdot 23$ & $231 \cdot 01$ & $222 \cdot 37$ & $222 \cdot 82$ & $213 \cdot 15$ \\
\hline
\end{tabular}




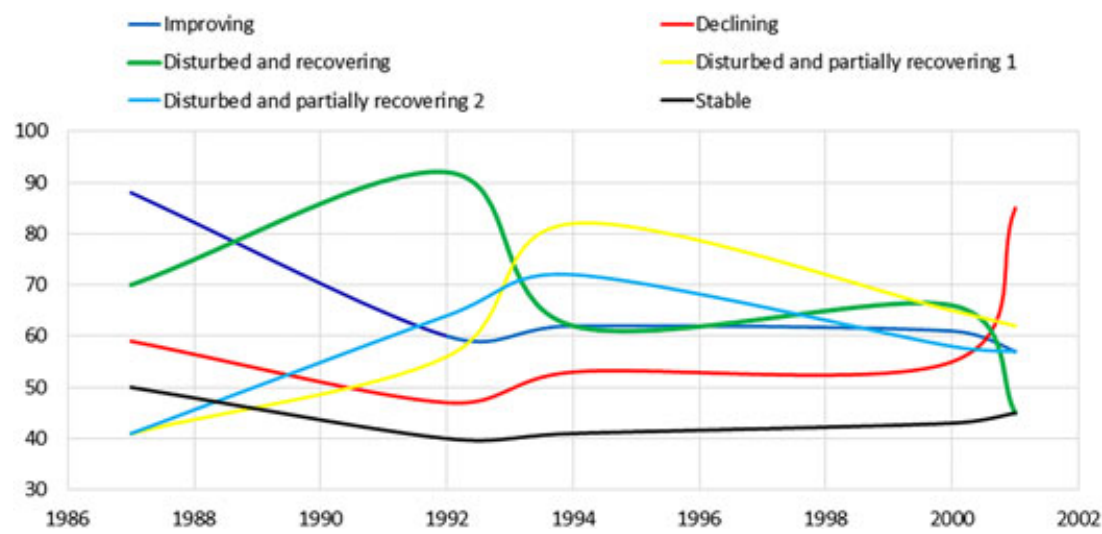

Figure 5. Examples of disturbance and regeneration/reforestation as seen in the validation aerial photography and as mapped by the presented methodology employing a conditional probability network (CPN). This figure is available in colour online at wileyonlinelibrary.com/journal/ldr.

until the vegetation achieves a sufficient density, and, therefore, some recent, slow-growing or sparse revegetated areas cannot be detected. Also, errors of commission may occur when other land cover types give a similar spectral response to perennial vegetation. The temporal smoothing of the CPN removes most of the transient cultivation effects that might cause these errors. However, there are cases where some errors of commission remain. Examples include cleared areas with persistent dark soil.

\section{Woody Perennial Vegetation Cover Density Trends}

Examples of temporal densities for sample pixels representing areas of stable, improving or declining WPVC trends, as well as areas that have been disturbed and are recovering, are shown in Figure 4. Figure 6 is a sample woody density trend map between 1987 and 2001 where quadratic and linear trends are displayed simultaneously. An overall improvement in the density of woody cover was found in most woody areas that were not disturbed by fire (shades of blue in Figure 6). A large number of woody areas in 1987 were found to be declining in terms of their density in WPVC mainly due to the two main fire events in the northwest and the east (in shades of red in Figure 6). The visualisation of the density trends six-band output file also revealed areas in the north of the study area that faced some disturbance but appear to be recovering back to 1987

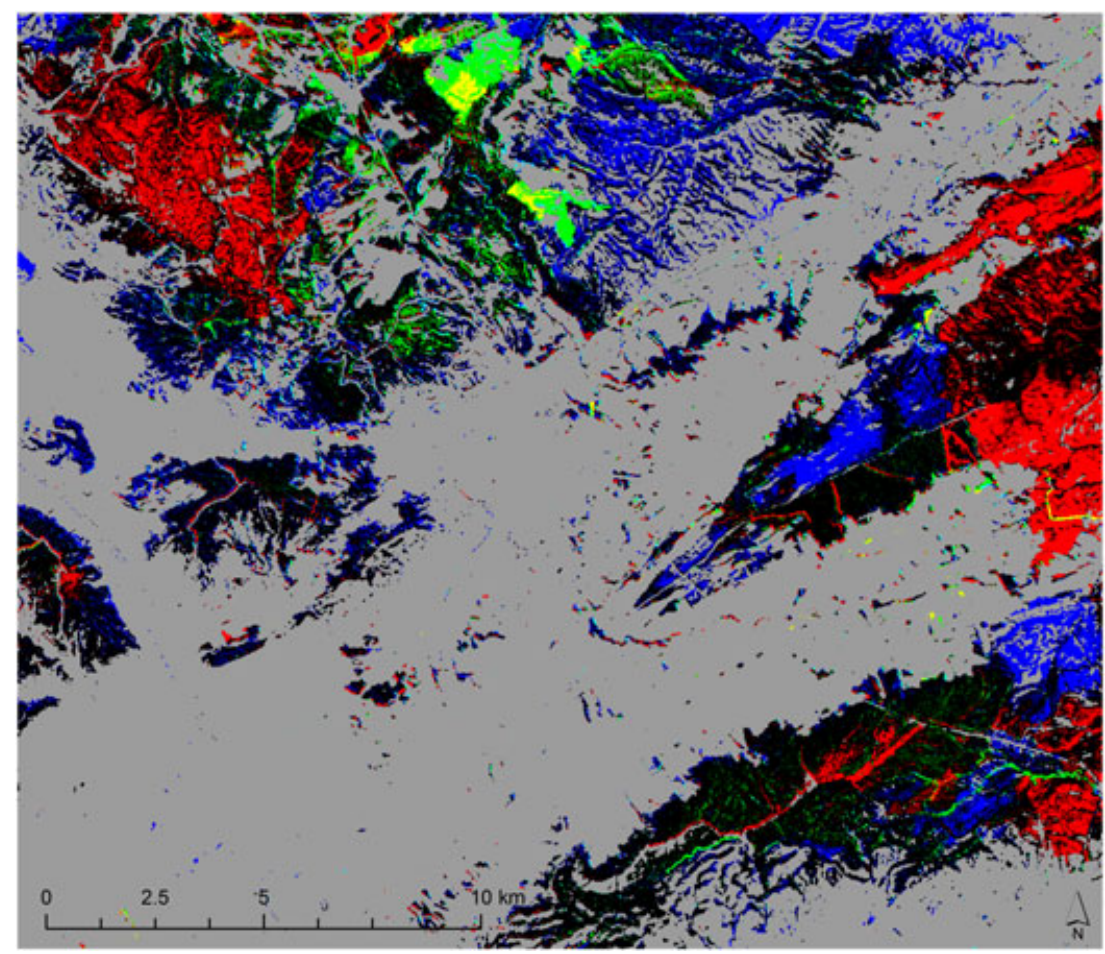

Figure 6. Linear and quadratic woody perennial vegetation cover (WPVC) temporal density trends. Shades of blue represent an increasing trend and shades of red a declining trend. Green areas are those that have been disturbed but are recovering; mixed colours (yellow and cyan) are areas that have been disturbed and only partially recovered. Stable WPVC areas, in black; stable non-WPVC areas, in grey. This figure is available in colour online at wileyonlinelibrary.com/ journal/ldr. 
woody cover density levels (shades of green in Figure 6) as well as areas that were disturbed but only partially recovered (yellow and cyan pixels in Figure 6).

The mapping of WPVC density trends allows for the distinction between various types of disturbance or recovery looking at index values and therefore facilitates the visual analysis of vegetation condition without the need to incorporate several 'from-to' GIS analyses. In this case study, for example, with five dates and two land cover types (woody and non-woody), the presence/absence change mapping entails the calculation of $2^{5}=32$ possible from-to cover changes. Increasing the time series to include more dates, for the more accurate delineation of WPVC, would complicate such an analysis exponentially $\left(2^{6}=64\right.$, $2^{7}=128$ and $2^{9}=256$ 'from-to' land cover change combinations!).

\section{CONCLUSIONS}

Mapping of vegetation cover typically provides a static description of the resource. Vegetation is, nonetheless, dynamic, and its change over time is perhaps the most significant information for management. In the Mediterranean region, there is a pressing need for accurate WPVC mapping methods that would allow for the identification of any decreasing trends in woody cover and density and the adaptation of measures for its reversal. The freely available Landsat archive can provide suitable spatial, spectral and temporal resolutions and the means to move from bitemporal to mapping trajectories of change, provided that accurate individual-year classifications can be achieved. The methodology presented here, devised by the CSIRO and based on multiple-year processing of Landsat data, proved to be a powerful monitoring tool of Mediterranean WPVC producing highly accurate WPVC maps. According to these maps, $20 \%$ of the area that was WPVC in 1987 experienced some disturbance by the end of the study period. Disturbance rates also doubled in the second half of the 14-year period.

Forested surfaces in the area are mainly composed of discontinuous pine trees mixed with Mediterranean woody shrubland species (i.e. Mediterranean maquis). The classification methodology allowed for a good detection of natural continuous vegetated areas with these characteristics as it was capable of discriminating from non-forested areas (such as olive or almond groves) or highly dispersed natural vegetation without enough continuity to be considered as forested areas. The spatiotemporal approach to classification had the effect of smoothing out single-date classification errors and removing some of the remaining terrain-induced error artefacts from the single-date prior probability maps.

The methodology also provided an insight in the trend of the density of woody vegetation cover allowing for an appraisal of any disturbance, with or without recuperation. Two major fire events, which are prevalent in the Mediterranean region in the very hot and dry summer months, were identified as the main drivers of the decline in the extent and density of WPVC in the area. It is suggested that a balance should be sought between the use of sufficient data for the study of a particular aspect of WPVC in Mediterranean environments and the complexity of the respective calculations.

\section{ACKNOWLEDGEMENTS}

This research was funded by an EU Marie Curie Actions Fellowship (contract number MOIF-CT-2005-008667). The authors are grateful to the Global Land Cover Facility (GLCF) of the University of Maryland for providing the free data and to SIG-oleícola and SIGPAC for the aerial orthophotos.

\section{REFERENCES}

AFP. 2009. Agence France-Presse: climate change fueling forest fires in Europe says Greenpeace, http://www.terradaily.com/reports/ Climate_change_fueling_forest_fires_in_Europe_Greenpeace_999.html (Accessed 23 June 2014).

Barua AK, Haque SMS. 2013. Soil characteristics and carbon sequestration potentials of vegetation in degraded hills of Chittagong, Bangladesh. Land Degradation \& Development 24: 63-71. DOI: 10.1002/ldr.1107.

Bravo-Espinosa M, Mendoza ME, Carlón-Allende T, Medina L, Sáenz-Reyes JT, Páez R. 2014. Effects of converting forest to avocado orchards on topsoil properties in the trans-Mexican volcanic system, Mexico. Land Degradation \& Development 25: 452-467. DOI: 10.1002/ldr.2163.

Berberoglu S, Akin A. 2009. Assessing different remote sensing techniques to detect land use/cover changes in the eastern Mediterranean. International Journal of Applied Earth Observation and Geoinformation 11: 46-53. DOI: 10.1016/j.jag.2008.06.002.

Bodart C, Eva H, Beuchle R, Raši R, Simonetti D, Stibig HJ, Brink A, Lindquist E, Achard F. 2011. Pre-processing of a sample of multi-scene and multi-date Landsat imagery used to monitor forest cover changes over the tropics. ISPRS Journal of Photogrammetry and Remote Sensing 66: $555-563$.

Bodí MB, Mataix-Solera J, Doerr SH, Cerdà A. 2011. The wettability of ash from burned vegetation and its relationship to Mediterranean plant species type, burn severity and total organic carbon content. Geoderma 160: 599-607. DOI: 10.1016/j.geoderma.2010.11.009.

Bonan GB. 2008. Forests and climate change: forcings, feedbacks, and the climate benefits of forests. Science 320: 1444-1449. DOI: $10.1016 / \mathrm{j}$. isprsjprs.2011.03.003.

Bonet A. 2004. Secondary succession of semi-arid Mediterranean old-fields in south-eastern Spain: insights for conservation and restoration of degraded lands. Journal of Arid Environments 56: 213-233.

Caccetta PA, Bryant G, Campbell NA, Chia J, Furby S, Kiiveri HT, Richards G, Wallace J, Wu X. 2003. Notes on mapping and monitoring forest change in Australia using remote sensing and other data. Proc. ISRSE Conference, Honolulu, USA.

Caccetta PA, Furby SL, O’Connell J, Wallace JF, Wu X. 2007. Continental monitoring: 34 years of land cover change using Landsat imagery. Proc. International Symposium on Remote Sensing of Environment, 25-29 June, San José, Costa Rica.

Camacho-De Coca F, García-Haro FJ, Gilabert MA, Meliá J. 2004. Vegetation cover seasonal changes assessment from TM imagery in a semi-arid landscape. International Journal of Remote Sensing 25: 3451-3476. DOI: 10.1080/01431160310001618761.

Campbell NA, Furby SL. 1994. Variable selection along canonical vectors. Australian Journal of Statistics 36: 177-183.

Cerdà A. 1998. The influence of geomorphological position and vegetation cover on the erosional and hydrological processes on a Mediterranean hillslope. Hydrological Processes 12: 661-671. DOI: 10.1002/(SICI) 1099-1085(19980615)12:7<1031::AID-HYP636>3.0.CO;2-V.

Cerdà A, Doerr SH. 2005. The influence of vegetation recovery on soil hydrology and erodibility following fire: an eleven-year research. International Journal of Wildland Fire 14: 423-437. DOI: 10.1071/WF05044. 
Cerdà A, Doerr SH. 2007. Soil wettability, runoff and erodibility of major dry-Mediterranean land use types on calcareous soils. Hydrological Processes 21: 2325-2336. DOI: 10.1002/hyp.6755.

Cerdà A, Imeson AC, Calvo A. 1995. Fire and aspect induced differences on the erodibility and hydrology of soils at La Costera, Valencia, Southeast Spain. Catena 24: 289-304.

Chrenková K, Mataix-Solera J, Dlapa P, Arcenegui V. 2014. Long-term changes in soil aggregation comparing forest and agricultural land use in different Mediterranean soil types. Geoderma 235-236: 290-299. DOI: 10.1016/j.geoderma.2014.07.025.

Cohen WB, Maiersperger TK, Yang Z, Gower ST, Turner DP, Ritts WD, Berterretche M, Running SW. 2003. Comparisons of land cover and LAI estimates derived from ETM+ and MODIS for four sites in North America: a quality assessment of 2000/2001 provisional MODIS products. Remote Sensing of Environment 88: 233-255. DOI: 10.1016/ j.rse.2003.06.006.

Coppin PR, Bauer ME. 1994. Processing of multitemporal Landsat TM imagery to optimize extraction of forest cover change features. IEEE Transactions on Geoscience and Remote Sensing 32: 918-927. DOI: 10.1109/36.298020

Coppin, PR, Bauer, ME. 1996. Digital change detection in forest ecosystems with remote sensing imagery. Remote Sensing Reviews 13: 207-234

Coppin P, Jonckheere I, Nackaerts K, Muys B, Lambin E. 2004. Digital change detection methods in ecosystem monitoring: a review. International Journal of Remote Sensing 25: 1565-1596. DOI: 10.1080/ 0143116031000101675.

Draper NR, Smith H. 1981. Applied regression analysis. Wiley: New York.

Foody GM. 2002. Status of land cover classification accuracy assessment. Remote Sensing of Environment 80: 185-201. DOI: 10.1016/S00344257(01)00295-4

Foody GM, Boyd DS. 1999. Detection of partial land cover change associated with the migration of inter-class transitional zones. International Journal of Remote Sensing 20: 2723-2740.

Furby SL. 2002. Land cover change: specification for remote sensing analysis. National Carbon Accounting System Technical Report 9. Australian Greenhouse Office, Canberra, http://citeseerx.ist.psu.edu/ viewdoc/download; jsessionid=9C2168F923E0ABE248FB20A310A731F7?doi=10.1.1. 124.7968\&rep=rep1\&type=pdf (Accessed 26 February 2015).

Gill TK, Phinn SR, Armston JD, Pailthorpe BA. 2009. Estimating treecover change in Australia: challenges of using the MODIS vegetation index product. International Journal of Remote Sensing 30: 1547-1565. DOI: $10.1080 / 01431160802509066$.

González-Alonso F, Merino-De-Miguel S, Roldán-Zamarrón A, García-Gigorro S, Cuevas JM. 2007. MERIS full resolution data for mapping level-ofdamage caused by forest fires: the Valencia de Alcantara event in August 2003. International Journal of Remote Sensing 28: 797-809. DOI: 10.1080/ 01431160600979115 .

Griffiths P, Kuemmerle T, Baumann M, Radeloff VC, Abrudanc IV, Lieskovsky J, Munteanu C, Ostapowicz K, Hostert P. 2014. Forest disturbances, forest recovery, and changes in forest types across the Carpathian ecoregion from 1985 to 2010 based on Landsat image composites. Remote Sensing of Environment 151: 72-88. DOI: 10.1016/j.rse.2013.04.022.

Hansen MC, Stehman SV, Potapov PV, Loveland TR, Townshend JRG, DeFries RS. 2008. Humid tropical forest clearing from 2000 to 2005 quantified by using multitemporal and multiresolution remotely sensed data. Proceedings of the National Academy of Sciences 105: 9439-9444. DOI: 10.1073/pnas.0804042105.

Hansen MC, Potapov PV, Moore R, Hancher M, Turubanova SA, Tyukavina A, Thau D, Stehman SV, Goetz SJ, Loveland TR, Kommareddy A, Egorov A, Chini L, Justice CO, Townshend JRG. 2013. High-resolution global maps of 21 st-century forest cover change. Science 342: 850-853. DOI: 10.1126/science.1244693.

Hilker T, Wulder MA, Coops NC. 2008. Update of forest inventory data with LIDAR and high spatial resolution satellite imagery. Canadian Journal of Remote Sensing 34: 5-12.

Huang C, Goward CN, Masek JG, Thomas N, Zhu Z, Vogelmann JE. 2010. An automated approach for reconstructing recent forest disturbance history using dense Landsat time series stacks. Remote Sensing of Environment 114: 183-198. DOI: 10.1016/j. rse.2009.08.017.

Kennedy RE, Cohen W, Schroeder TA. 2007. Trajectory-based change detection for automated characterization of forest disturbance dynamics.
Remote Sensing of Environment 110: 370-386. DOI: 10.1016/j. rse.2007.03.010.

Kiiveri HT, Caccetta PA. 1998. Image fusion with conditional probability networks for monitoring salinisation of farmland. Digital Signal Processing 8: 225-230.

Kiiveri HT, Caccetta PA, Evans F. 2001. Use of conditional probability networks for environmental monitoring. International Journal of Remote Sensing 22: 1173-1190. DOI: 10.1080/01431160151144305.

Kuemmerle T, Chaskovskyy O, Knorn J, Radeloff VC, Kruhlov I, Keeton WS, Hostert P. 2009. Forest cover change and illegal logging in the Ukrainian Carpathians in the transition period from 1988 to 2007. Remote Sensing of Environment 113: 1194-1207. DOI: 10.1016/j. rse.2009.02.006.

Lee JW, Park CM, Rhee H. 2013. Revegetation of decomposed granite roadcuts in Korea: developing Digger, evaluating cost effectiveness, and determining dimension of drilling holes, revegetation species, and mulching treatment. Land Degradation \& Development 24: 591-604. DOI: $10.1002 / \mathrm{ldr} .2248$.

Lehmann EA, Wallace JF, Caccetta PA, Furby SL, Zdunic K. 2012. Forest cover trends from time series Landsat data for the Australian continent. International Journal of Applied Earth Observation and Geoinformation 21: 453-462. DOI: 10.1016/j.jag.2012.06.005.

Liu L, Tang H, Caccetta PA, Lehmann EA, Hu Y, Wu X. 2013. Mapping afforestation and deforestation from 1974 to 2012 using Landsat timeseries stacks in Yulin District, a key region of the Three-North Shelter region, China. Environmental Monitoring and Assessment 185: 99499965. DOI: 10.1007/s10661-013-3304-2.

MA. 2005. Millennium ecosystem assessment. Ecosystems and human well-being: current state and trends. Island Press: Washington D.C.; 137.

Magnussen S, Boudewyn P, Wulder M. 2004. Contextual classification of Landsat TM images to forest inventory cover types. International Journal of Remote Sensing 25: 2421-2440. DOI: 10.1080/ 01431160310001642296.

Margono BA, Turubanova S, Zhuravleva I, Potapov P, Tyukavina A, Baccini A, Goetz S, Hansen MC. 2012. Mapping and monitoring deforestation and forest degradation in Sumatra (Indonesia) using Landsat time series data sets from 1990 to 2010. Environmental Research Letters 7. DOI:10.1088/1748-9326/7/3/034010.

Muñoz-Villers LE, López-Blanco J. 2008. Land use/cover changes using Landsat TM/ETM images in a tropical and biodiverse mountainous area of central-eastern Mexico. International Journal of Remote Sensing 29: 71-93. DOI: 10.1080/01431160701280967.

Nilsson M, Holm S, Wallerman J, Reese H, Olsson H. 2009. Estimating annual cuttings using multi-temporal satellite data and field data from the Swedish NFI. International Journal of Remote Sensing 30: 5109-5116. DOI: 10.1080/01431160903022910.

Onur I, Maktav D, Sari M, Sönmez NK. 2009. Change detection of land cover and land use using remote sensing and GIS: a case study in Kemer, Turkey. International Journal of Remote Sensing 30: 1749-1757. DOI: 10.1080/01431160802639665.

Quiñonero-Rubio JM, Nadeu E, Boix-Fayos C, Vente J. 2015. Evaluation of the effectiveness of forest restoration and check-dams to reduce catchment sediment yield. Land Degradation \& Development . DOI:10.1002/ ldr.2331.

Richards JA. 2013. Remote sensing digital image analysis: an introduction, 5th edn. Springer-Verlag: Berlin Heidelberg; 494.

Röder A, Hill J, Duguy B, Alloza JA, Vallejo R. 2008. Using long time series of Landsat data to monitor fire events and post-fire dynamics and identify driving factors. A case study in the Ayora region (eastern Spain). Remote Sensing of Environment 112: 259-273. DOI: 10.1016/j. rse.2007.05.001.

Symeonakis E, Calvo-Cases A, Arnau-Rosalen E. 2007. Land use change and land degradation in south-eastern Mediterranean Spain. Environmental Management 40: 80-94. DOI: 10.1007/s00267-0040059-0.

Teillet PM, Guindon B, Goodenough DG. 1982. On the slope-aspect correction of multispectral scanner data. Canadian Journal of Remote Sensing 8: 84-106.

Tucker CJ, Grant DM, Dykstra JD. 2004. NASA's global orthorectified Landsat data set. Photogrammetric Engineering and Remote Sensing 70: $313-322$.

Vermote E, Tanré D, Deuzé JL, Herman M, Morcrette JJ. 1994. Second simulation of the satellite signal in the solar spectrum (6S), 6S user guide version 0 . 


\section{MULTI-TEMPORAL FOREST COVER CHANGE AND FOREST DENSITY TREND DETECTION}

Wallace JF, Behn G, Furby SL. 2006. Vegetation condition assessment and monitoring from sequences of satellite imagery. Ecological Management and Restoration 7: 33-36. DOI: 10.1111/j.14428903.2006.00289.x.

Wu X, Danaher T, Wallace JF, Campbell NA. 2001. A BRDF-corrected Landsat 7 mosaic of the Australian continent. International Geoscience and Remote Sensing Symposium (IGARSS) 7: 3274-3276.
Wu X, Furby SL, Wallace JF. 2004. An approach for terrain illumination correction. Proc. Australasian Remote Sensing and Photogrammetry Conference, Fremantle

Wu X, Caccetta PA, Furby SL, Wallace JF, Zhu M. 2005. Remote sensing analysis of land cover change. In: Proceedings of International Symposium on Spatio-temporal Modeling, Spatial Reasoning, Analysis, Data Mining and Data Fusion, 27-29 August, Beijing, China. 